Original Article

\title{
Use of Misoprostol in Term pregnant women for Good Delivery Outcome: Experience at a tertiary care Hospital in Dhaka
}

\author{
Aftabun Nahar ${ }^{1}$, Rifat Sultana ${ }^{2}$, Fatema Mahbooba Akter $^{3}$, Munira Ferdausi ${ }^{4}$, M Abdullah Yusuf ${ }^{5}$, \\ Kamrun Nahar ${ }^{6}$
}

\begin{abstract}
Background: Use of misoprostol in term pregnancy is very useful for the better outcome during delivery. Objective: The purpose of the present study was to see the delivery outcome among the term pregnant women. Methodology: This cohort study was carried out in the Department of Obstetrics and Gynaecology at Sir Salimullah Medical College and Mitford Hospital during the period from $1^{\text {st }}$ September 2005 to $28^{\text {th }}$ February 2006. Primi or second gravida patients with the gestational age between 37 weeks to 42 weeks in singleton pregnancy with cephalic presentation and not in labour who came for delivery purposes during the study period at any age were selected as study population. After proper selection of the cases, induction of labour (IOL) was done by applying Tab Misoprostol $50 \mathrm{mcg}$ in the posterior vaginal fornix. Purpose of induction of labour was successful when vaginal delivery occurred without any untoward side effects and without any surgical interference. Result: Out of 60 pregnant women $21(35 \%)$ patients had unfavourable Bishops' score with 3-5 and 39 (65\%) patients had favorable Bishops' score with 6-10. This table shows that 39 patients had favourable pre- induction cervical score, among them $79 \%$ had delivered vaginally and $21 \%$ had undergone LUCS. 21 patients had unfavourable cervix, among them 57\% experienced vaginal delivery and $43 \%$ experienced LUCS. Out of all study population $60 \%$ of study population who were primigravide had vaginal delivery in $67 \%$ cases and caesarean section in $33 \%$ cases and among $40 \% 2^{\text {nd }}$ gravida cases vaginal delivery was $79 \%$ and caesarean delivery was $21 \%$. Conclusion: In conclusion the use of misoprostol during term pregnancy is significantly related with the normal delivery. [Journal of Science Foundation 2014;12(2):22-26]
\end{abstract}

Keywords: Misoprostol; term pregnancy; delivery; caesarean section

\section{Introduction}

Induction of labour is an integral part of modern obstetric practice and should be simple, safe, effective and preferably non invasive (Calder 1999). There are different methods of induction of labour like medical, surgical and combined. There is no ideal accepted method of induction of labour. History says, from ancient time many methods were used for induction of labour. Currently oxytocin and prostaglandins are randomly used for induction of labour (Dutta 2005). Oxytocin is the drug of choice for labour induction when the cervix is favourable. At present oxytocin is the prime labour induction drug available in our country (Harman 2001). Prostaglandins are equally effective as that of oxytocin but are more effective in cases of

\footnotetext{
${ }^{1}$ Senior Consultant, Department of Obstetrics \& Gynaecology, Shaheed Suhrawardy Medical College \& Hospital, Dhaka, Bangladesh ${ }^{2}$ Junior Consultant (Gynaecology), Upazilla Health Complex, Nawabganj, Dhaka, Bangladesh

${ }^{3}$ Junior Consultant, Department of Obstetrics \& Gynaecology, Shaheed Suhrawardy Medical College \& Hospital, Dhaka, Bangladesh

${ }^{4}$ Associate Professor, Department of Obstetrics \& Gynaecology, Shaheed Suhrawardy Medical College \& Hospital, Dhaka, Bangladesh

${ }^{5}$ Assistant Professor, Department of Microbiology, National Institute of Neurosciences \& Hospital, Dhaka, Bangladesh

${ }^{6}$ Medical Officer, Maternal child Health and Family Planning, Kotiati, Kishorganj, Bangladesh
}

Corresponding author: Dr. Aftabun Nahar, Senior Consultant, Department of Gynaecology \& Obstetrics, Shaheed Suhrawardy Medical College, Sher-E-Bangla Nagar, Dhaka-1207, Bangladesh; Email: draftabun@ gmail.com; Cell no.: +8801711339407 
intrauterine fetal death or early gestational period with unfavourable cervix and have got no diuretic effect (Kwon et al., 2001).

Prostaglandins are hormones naturally present in the uterus that cause contractions during labour. Currently, a prostaglandin (Misoprostol), a synthetic Prostaglandin $\mathrm{E}_{1}$ analogue marketed as a gastrointestinal mucosal protection agent is a safe, easily available, efficacious and inexpensive for use in cervical ripening and labour induction. Latest studies show that, prostaglandin is superior to oxytocin as prostaglandin is local hormone which softens the cervix directly. In fact, prostaglandin provides an excellent alternative to conventional oxytocin for induction of labour. There has been a growing body of literature to suggest that misoprostol is highly effective and safe as a labour inducing agent (Sanchez-Ramos et al., 1999). It is less expensive, can be stored at room temperature and has fewer side effects. The use of misoprostol results in a shorter induction to delivery time, a reduction in rate of caesarean section and without any adverse effect on the mother and the neonatal outcomes. It is rapidly absorbed and is more effective than oxytocin or dinoproston for induction of labour.

Misoprostol is a cheap \& stable $\mathrm{PGE}_{1}$ analogue that is active both by the vaginal \& oral route of administration for cervical ripening and induction. When it is given orally, it is rapidly absorbed by the gastrointestinal tract and undergoes de-esterification to its free acid, which is responsible for its clinical activity. The peak concentration and half-life of misoprostol acid, the active metabolite, are 12 and 21 minutes, respectively (Zieman et al., 1997). The total systemic bioavailability of vaginally administered misoprostol is three times greater than that of orally administered misoprostol (Sanchez-Ramos et al., 1998). In Bangladesh, misoprostol is available as tablet form, each containing $200 \mathrm{mcg}$. A variety of clinical practices are used in different centers for management of induction labour \& consequently there are no agreed guideline that describe the method of induction of labour (Wood et al., 2001). In 1970 when more reliable methods become available, labour induction rates rose about $50 \%$ in specialized center (Wood et al., 2001). The success of induction depends to a large extent on the consistency; compliance and configuration of the uterine cervix (Shetty et al., 2001). In $10 \%$ of all pregnant women have an unfavourable cervix and require labour to be induced (Glmezoglu et al., 2001). Therefore induction of labour to be effective it is not sufficient simply to stimulate contractility of the myometrium.

The induction method must endeavour as far as possible to replicate the events of normal parturition. In addition to generating myometrial contractility it must induce the changes of cervical ripening if these have not occurred naturally (Dutta 2005). Although the safety and reliability of induction has greatly increased in recent years, in more advanced countries because of development of newer and better induction techniques and modern facilities for foetal and maternal monitoring, we are still in position where we have to depend mainly on clinical judgment and this imposes several limitations. However, in absence of sophisticated monitoring techniques patients are induced everyday practice with best possible efforts and attention, cases are managed to have a better obstetric outcome. In this study, the role of vaginal misoprostol for the induction of labour was evaluated in the department of Obstetrics and Gynaecology at a tertiary care hospital in Dhaka city.

\section{Methodology}

This is a prospective study that was carried out in the department of Obstetric and Gynaecology in Sir Salimullah Medical College and Mitford Hospital during the period from $1^{\text {st }}$ September 2005 to $28^{\text {th }}$ February 2006. 60 cases were selected from patients who came for delivery purposes during the study period. Primigravida or second gravida with gestational age between 37 weeks to 42 weeks, Patients not in labour, Singleton pregnancy with vertex presentation, unfavourable cervix (Bishop's score $<6$ ) and intact membrane were included in this study. Cephalopelvic disproportion, multiple pregnancies, fetal distress, malpresentation, H/O asthma, Any contraindication to normal vaginal delivery, $\mathrm{H} / \mathrm{O}$ uterine surgery like LUCS, Myomectomy or Hysterotomy operation, ruptured membrane cases were excluded from this study. The cases were primigravida or second gravida with the gestational age between 37 weeks to 42 weeks with cephalic presentation and not in labour. The methods of induction of labour by vaginal Misoprostol were explained to the patients who volunteered and were selected for the study. Consent was taken from every patient. All relevant clinical information of the cases was recorded systematically in a predesigned clinical data sheet. At first, proper history of the patient was taken which included period of amenorrhoea, H/O 
antenatal check up, immunization, gravida, last menstrual period etc. Then general examination of the patient was done to detect any disease which complicates pregnancy or labour. This was followed by per abdominal examination to see foetal presentation, lie, foetal heart sound. Then per vaginal examination was done to do the clinical pelvimetry and Bishop's scoring. If the pelvis was adequate for normal vaginal delivery then irrespective of any Bishop's score cases were selected for induction of labour. After proper selection of the cases, induction of labour was done by applying tab misoprostol $50 \mathrm{mcg}$ in the posterior vaginal fornix. Misoprostol is available in our country as tab cytomis each containing $200 \mathrm{mcg}$. So, $1 / 4^{\text {th }}$ of the tablet was used. Close observation of the patient was done to see when the labour started. If the labour did not start then the same dose was repeated up to the establishment of true labour pain. When the labour started close monitoring of the patient and the foetus were done. When the labour went into the active phase then further application of Tab cytomis was stopped and the partograph was maintained. Following the Partograph the progress of labour was monitored. If the labour was seen to be prolonged then augmentation was done by giving oxytocin drip. Close observation of the progress of labour was done to see whether there was any untoward effect of induction of labour like tachysystole, hyperstimulation or foetal distress. After collecting all the data, analysis has been done by using SPSS and the results are displayed in tables and diagrams. Discussions have been done by comparing the results of the study with the results from similar study done in home and abroad.

\section{Result}

A total number of 60 pregnant women were recruited for this study as per inclusion and exclusion criteria. Out of 60 pregnant women $36(60 \%)$ patients were parimigravida and $24(40 \%)$ patients were second gravid. The mean age with standard deviation of the study population was $24.08 \pm 3.25$ years with the range of 18 to 31 years. The mean Bishop's Score was $6.2 \pm 1.76$ with a minimum value of 3 and maximum value 10 . The mean gestational age of the study population was $40.41 \pm 1.1$ weeks with the minimum and maximum value of 38 and 42 weeks respectively. The mean induction delivery interval was 11.1 4.4 hours with the range of 4-24 hours (Table 1 ).

\section{Table 1: Details of Patients at Induction}

\begin{tabular}{|l|l|}
\hline Variables & \multicolumn{1}{|c|}{ Value } \\
\hline Primigravida & $36(60 \%)$ \\
\hline Second gravida & $24(40 \%)$ \\
\hline Age [Mean \pm SD (Range) in years] & $24.08 \pm 3.25(18-31)$ \\
\hline Bishop's Score [Mean \pm SD (Range)] & $6.2 \pm 1.76(3-10)$ \\
\hline Gestational Age [Mean \pm SD (Range) weeks)] & $40.41 \pm 1.1(38-42)$ \\
\hline Induction delivery interval (hours) & $11.1 \pm 4.4(4-24)$ \\
\hline
\end{tabular}

Out of 60 patients 31(51.7\%) patients needed only 1 dose of misoprostol and 24(40\%) patients needed 2 doses and only $5(8.3 \%)$ patients' needed 3 doses of Misoprostal (Table 2).

Table 2: Total Doses of Misoprostol Given

\begin{tabular}{|c|c|c|}
\hline Total Doses & Frequency & Percentage \\
\hline 1 & 31 & 51.7 \\
\hline 2 & 24 & 40.0 \\
\hline 3 & 5 & 8.3 \\
\hline
\end{tabular}

Out of 60 pregnant women 21 (35\%) patients had unfavourable Bishops' score with 3-5 and 39 (65\%) patients had favorable Bishops' score with 6-10. This table shows that 39 patients had favourable preinduction cervical score, among them $79 \%$ had delivered vaginally and $21 \%$ had undergone LUCS. 21 patients had unfavourable cervix, among them 57\% experienced vaginal delivery and $43 \%$ experienced LUCS (Table 3). Out of all study population $60 \%$ of study population who were primigravide had vaginal delivery in $67 \%$ cases and caesarean section in $33 \%$ cases and among $40 \% 2^{\text {nd }}$ gravida cases vaginal delivery was $79 \%$ and caesarean delivery was $21 \%$ (Table 4 ). 


\section{Discussion}

A well designed prospective study was done to evaluate the outcome of induction of labour by vaginal Misoprostol in term pregnancy in the department of Obstetrics and Gynaecology, Sir Salimullah Medical College and Mitford Hospital, Dhaka from September 2005 to February 2006. For this study 60 patients were selected after fulfilling the inclusion and exclusion criteria. In each case, induction of labour was done after taking proper history and all the information were recorded in the data collection sheets. All the records were studied with analysis of various aspects of the cases in relation to the present study. The study was conducted to evaluate the outcome of induction of labour in term pregnancy to see whether routine induction of labour increases the rate of caesarean section, to find out the cause of failure of aim of induction and any complication of induction of labour.

\section{Table 3: Relation of Cervical Score with Mode of Delivery}

\begin{tabular}{|l|c|c|c|}
\hline \multirow{2}{*}{ Mode of delivery } & \multicolumn{2}{|c|}{ Cervical Score } & \multirow{2}{*}{ Total } \\
\cline { 2 - 3 } & Fabourable & Unfabourable & \\
\hline Vaginal delivery & $31(79.0 \%)$ & $12(57.0 \%)$ & $43(71.7 \%)$ \\
\hline LUCS & $8(21.0 \%)$ & $9(43.0 \%)$ & $17(28.3 \%$ \\
\hline Total & $\mathbf{3 9}(\mathbf{1 0 0 . 0 \%})$ & $\mathbf{2 1}(\mathbf{1 0 0 . 0 \%})$ & $\mathbf{6 0}(\mathbf{1 0 0 . 0 \%})$ \\
\hline
\end{tabular}

*Favourable score $=\geq 6$; Unfavourable score $=<6$; Chi-square test has been performed to see the level of significance; $p$ value 0.0001

In the study out of 60 patients $36(60 \%)$ cases were primigravida and $24(40 \%)$ cases were second gravida. The mean age was $24.08 \pm 3.25$ years. The lowest aged patient was 18 years and eldest one was 31 years. It is promising and hopeful regarding safe mother that all the patients were in early age group. Mean gestational age was $40.41 \pm 1.1$ weeks range was $38-42$ weeks. Mean Bishop's score was $6.2 \pm 1.76$ and range was 3-10. In analysis of indications of induction of labour - Post dated pregnancy was on the top of the list the number of which was 33 (55\%), Preeclampsia was in the second position the number of which was 10 $(16.65 \%)$.

Among 60 patients $43(71.6 \%)$ patients delivered vaginally and $17(28.4 \%)$ patients needed caesarean section. Again out of 43 vaginal delivery $22(51.20 \%)$ patients needed single dose of Misoprostol tablet and $21(48.8 \%)$ patients needed more than one dose. In this study there was no failure of induction of labour and labour was established in 100\% cases. Another similar study done by Jahan (1990) showed that $63 \%$ patient with unfavourable cervix required caesarean section after induction of labour and in that study no prostaglandins was used for cervical ripening. But in this study, because of prostaglandins the percentage of caesarean section was only $43 \%$ and vaginal delivery was $57 \%$. In another study done by Kenedy et al (1982), the mean age of the patients was 26.6 years and mean cervical score was 6.6. But in this study the mean age was $24.08 \pm 3.25$ years and mean Bishop's score was $6.2 \pm 1.76$.

Of total 60 patients $17(28.4 \%)$ cases needed caesarean section due to failure of aim of induction. In this study patient with both favourable and unfavourable cervix were taken. The study showed better outcome in patient with favourable cervix. Regarding pre induction cervical score 39(65\%) cases had favourable score. Among them $31(79 \%)$ cases delivered vaginally and $8(21 \%)$ cases had undergone caesarean section. And among $21(35 \%)$ unfavourable cases $12(57 \%)$ cases experienced vaginal delivery and 9(43\%) cases had undergone caesarean section. This study indicates that there is a direct potential relationship between cervical condition (Bishop's score) and vaginal delivery.

Table 4: Mode of Delivery In Relation to Gravida

\begin{tabular}{|l|c|c|l|}
\hline Mode of delivery & Primigravida & $\mathbf{2}^{\text {nd }}$ Gravida & Total \\
\hline Vaginal delivery & $24(67.0 \%)$ & $19(79.0 \%)$ & $43(71.7 \%)$ \\
\hline Caesarian delivery & $12(33.0 \%)$ & $5(21.0 \%)$ & $17(28.3 \%)$ \\
\hline Total & $\mathbf{3 6}(\mathbf{1 0 0 . 0 \%})$ & $\mathbf{2 4}(\mathbf{1 0 0 . 0 \%})$ & $\mathbf{6 0}(\mathbf{1 0 0 . 0} \%)$ \\
\hline
\end{tabular}

*Chi-square test has been performed to see the level of significance; $p$ value 0.0001 
There is a similar type of study carried out by Amiruzzaman (2004) on 65 patients and the mean age of patients was 24.65 years and in this study it is $24.08 \pm 3.25$ years, which is almost similar. In this study, in the analysis of indication of induction of labour prolonged pregnancy is on the top which is same in this study. In this study 48 (73.8\%) cases were delivered vaginally and 17 (26.1\%) cases needed caesarean section- the results are almost similar to that of this study. But out of 48 vaginal delivery $83.3 \%$ patients needed single dose of oral Misoprostol tablet and $16.7 \%$ needed more than one dose. But in this study $51.2 \%$ cases needed one dose of vaginal Misoprostol and 48.8\% needed more than one tablet. Regarding Neonatal outcome in his study there was one fresh stillbirth such untoward outcome had not occurred in this study.

Mode of delivery in relation to gravidity, it is seen that multigravida (79\%) has more percentage of vaginal delivery than that of primigravida $(67 \%)$ and caesarean delivery is more in cases of primigravida (33\%) than that of multigravida (21\%). Regarding induction delivery interval, the interval between IOL and onset of labour was significantly shorter. Mean induction delivery interval was of $11.1 \pm 4.4 \mathrm{hrs}$. Routine induction was done in uncomplicated post dated pregnancy and with some indications with term pregnancy. As antenatal foetal monitoring facilities are limited and patient compliance is very poor in our country, this study was designed to see the outcome of routine induction of labour in term pregnancy rather than continuing the pregnancy to have spontaneous labour which may increase the perinatal morbidity and mortality. In this study it was found that due to routine induction of labour, vaginal delivery rate was more in multigravida (79\%) less in primigravida (67\%) and caesarean section rate was less in multigravida (21\%) and more in primigravida (33\%). These results are comparable with a study done by Parry et al (1998). In that study in multigravida, induction of labour was associated with a significant reduction in incidence of caesarean section from $22 \%$ in the control group to $11 \%$ in the induced group, for primigravida the difference was in opposite direction but did not reach the significance induced group $31 \%$ to control group $24 \%$. So these appear to be the evidence for multiparous women that induction of labour is associated with improved vaginal delivery outcome.

\section{Conclusion}

In the conclusion, it can be said that the use of Misoprostol results in a shorter induction to delivery time, a reduction in the rate of caesarean delivery and also did not appear to produce miserable adverse effects on the method of delivery or the foetus. There is increasing evidence that Misoprostol, administered vaginally, is as effective as conventional methods of induction of labour.

\section{References}

Amiruzzaman M. Use of Oral Prostaglandin for Induction of labour: Department of Obstetrics and Gynaecology, Rangpur Medical College Hospital, Rangpur, Bangladesh, 2004

Calder AA. Induction \& Augmentation of Labour: Edited by D. Keith Edmonds; Dewhurst's Textbook of Obstetrics and Gynaecology for Postgraduates. 6th edition Oxford; Blackwell Science Ltd; 1999 pp. 252-257

Dutta DC. Text Book Of Obstetrics including Perinatology and Contraception: $6^{\text {th }}$ edition 2005: New Central Book Agency(P) Ltd. 8/1 Chintamoni Das Lane, Calcutta 700 009(India): Induction of Labour:Page:520.

Glmezoglu AM, Villar J, Ngoc NTN, Piaggio G, Carroli G, Adetoro L, Abdel-Aleem H, Cheng L, Hofmeyr GJ, Lumbiganon P. WHO multicentre randomized trial of misoprostol in the management of the third stage of labour. Lancet 2001;358:689-695

Harman JH. Current Trends in Cervical Ripening and Labour Induction, 2001

Jahan S. Clinical study of the indications and outcome of induction of labour at I.P.G.M\&R. Bangladesh College of Physicians and Surgeons: 1990

Kennedy JH, Stewart $\mathrm{P}$, et al. Induction of Labour: a comparison of a single prostaglandin $\mathrm{E}_{2}$ vaginal tablet with amniotomy and intravenous oxytocin. Br Obstet Gynaecol 1982;89:704-707

Kwon JS, Davies GAL, Mackenzie VP. A comparison of oral and vaginal misoprostol for induction of labour at term: a randomised trial. BJOG: An International Journal of Obstetrics \& Gynaecology 2001;108:23-26

Parry E, Parry D, Pattison N. Induction of labour for post term pregnancy: An observational study; Department of Obstetrics and Gynaecology; National Women's Hospital, Auckland, New Zealand. Aust-NZ J Obstet Gynaecol, 1998;38:3:275

Sanchez-Ramos L, Kaunitz AM, Del Valle GO, Delke I, Schroeder PA, Briones DK. Labor induction with the prostaglandin E1 methyl analogue misoprostol versus oxytocin: a randomized trial. Obstetrics \& Gynecology 1999;81:332-336

Sanchez-Ramos L, Peterson DE, Delke I, Gaudier FL, Kaunitz AM. Labor induction with prostaglandin E1 misoprostol compared with dinoprostone vaginal insert: a randomized trial. Obstetrics \& Gynecology 1998;91:401-405

Shetty A, Danielian P, Templeton A. A comparison of oral and vaginal misoprostol tablets in induction of labour at term. BJOG: An International Journal of Obstetrics \& Gynaecology 2001;108:238-243

Wood AJJ, Goldberg AB, Greenberg MB, Darney PD. Misoprostol and pregnancy. New England J Med 2001;344:38-47

Zieman M, Fong SK, Benowitz NL, Banskter D, Darney PD. Absorption Kinetics of misoprpstol with oral or vaginal administration. Obstet Gynecol 1997; 90: 88-92 